\title{
Effectiveness of low dose versus high dose oxytocin regimen for induction of labour
}

\author{
Paridhi Gupta*, Indu Chawla, Sonal Gupta
}

Department of Obstetrics and Gynecology, ABVIMS and Dr. RML Hospital, New Delhi, India

Received: 22 February 2021

Accepted: 01 April 2021

\section{*Correspondence:}

Dr. Paridhi Gupta,

E-mail: paridhi.gupta257@gmail.com

Copyright: (C) the author(s), publisher and licensee Medip Academy. This is an open-access article distributed under the terms of the Creative Commons Attribution Non-Commercial License, which permits unrestricted non-commercial use, distribution, and reproduction in any medium, provided the original work is properly cited.

\begin{abstract}
Background: Induction of labour is an indispensable part of modern obstetrics and certainly one of the most frequently performed obstetric procedure in the world. Oxytocin, being the most common inducing agent with multiple protocols being practiced, further research is required for the establishment of better protocol with optimal maternal and neonatal outcomes.

Methods: Randomized comparative study including 100 term nulliparous women (randomized into high dose, groupI and low dose, group-II with 50 patients in each group) was done. High dose regimen was started with $4 \mathrm{mu} / \mathrm{min}$ with increment of $4 \mathrm{mu} / \mathrm{min}$ up to a maximum of $32 \mathrm{mu} / \mathrm{min}$ and low dose regimen was started with $2 \mathrm{mu} / \mathrm{min}$ with increment of $2 \mathrm{mu} / \mathrm{min}$ up to a maximum of $32 \mathrm{mu} / \mathrm{min}$. Induction to delivery interval was the primary outcome. Secondary outcomes noted were rate of caesarean section, tachysytole with or without fetal distress, failed induction, maternal outcomes like need for instrumental vaginal delivery, PPH and choriamnionitis, neonatal outcomes like NICU admission, umbilical cord $\mathrm{pH}$ and apgar score.

Results: There was significant reduction seen in induction to delivery interval among those induced with high dose oxytocin regimen. It was found to be $6.96 \pm 3.77$ hours in group-I and $9.05 \pm 4.65$ hours in group-II (p value 0.034 ). Though incidence of tachysystole was more in high dose regimen, it was not statistically significant. No significant difference was seen in secondary outcomes.

Conclusions: On the basis of present study, high dose oxytocin regimen can be considered for induction of labour as it has same effects as that of low dose regimen with lesser induction to delivery interval.
\end{abstract}

Keywords: Chorioamnionitis, Failed induction, Induction of labour, Tachysystole

\section{INTRODUCTION}

Induction of labour (IOL) refers to artificial stimulation of uterine contractions before the true onset of spontaneous labour in order to achieve vaginal delivery. ${ }^{1}$ The goal of labor induction is always to ensure the best possible outcome for mother and newborn. IOL should be performed only when there is a clear medical indication for it and the expected benefits outweigh its potential harms. Wherever possible, it has to be carried out in facilities where caesarean section can be performed. ${ }^{2}$ The incidence of labour induction has continued to rise over the past several decades. In developed countries, the number of infants delivered at term following induction of labour is as high as one in four deliveries that is approximately $25 \%$.

The World Health Organization (2011) Global Survey on maternal and perinatal Health was conducted in 24 countries including around 3,00,000 observations. It showed that $9.6 \%$ of them were delivered by labour induction. The survey found that African countries have lower rates of induction of labour (lowest: Niger 1.4\%) compared with Asian and Latin American countries (highest: Sri Lanka 35.5\%). ${ }^{3}$ 
Oxytocin is the most common inducing agent used worldwide. There are mainly two types of regimens that are widely studied, high dose and low dose oxytocin regimen. Low dose regimen starts with $1-2 \mathrm{mu} / \mathrm{min}$ with increment of $1-2 \mathrm{mu} / \mathrm{min}$ every $30 \mathrm{~min}$ maximum up to $32 \mathrm{mu} / \mathrm{min}$ and high dose regimen starts with 4-6 $\mathrm{mu} / \mathrm{min}$ with increment of 4-6 mu/min every 30min maximum up to $32 \mathrm{mu} / \mathrm{min}$.

The Royal college of obstetricians and gynecologists (RCOG) recommends an initial dose of $1-2 \mathrm{mu} / \mathrm{min}$ with arithmetic increments at $30 \mathrm{~min}$ intervals until a maximum of $32 \mathrm{mu} / \mathrm{min}^{5}$ The American college of obstetricians and gynecologists (ACOG) recommends an initial dose of $1-2 \mathrm{mu} / \mathrm{min}$ with increments of $1-2 \mathrm{mu} / \mathrm{min}$ at 30 minute intervals until every $2-3$ min contractions, up to a maximum of $42 \mathrm{mu} / \mathrm{min}^{6}$

Cochrane systemic review and other studies have found high dose oxytocin regimen to be associated with shorter induction delivery interval compared to low dose regimen. ${ }^{7-10}$ High dose oxytocin has also been associated with decrease in caesarean section. ${ }^{7}$ However, study by Prichard $\mathrm{N}$ et al have shown no significant difference in the rates of caesarean section between both the oxytocin regimens. ${ }^{11}$ High dose oxytocin has high risk of excessive uterine contraction or tachysystole (more than or equal to 5 contractions in 10 minutes). The regimen has been found to be associated with several maternal adverse effects like hyponatremia, hypotension, arrhythmia, tachysystole and neonatal adverse effects such as seizures, hyperbilirubinemia, retinal haemorrhages, fetal distress. ${ }^{9}$ Low dose regimen has prolonged induction delivery interval with better safety profile with fewer episodes of hyperstimulation. ${ }^{12}$ The increased induction to delivery interval that occurs with low dose regimen may increase the chances for fetal infection and chorioamionitis.

Current induction of labour regimens include both high and low dose regimens but evidence is not strong enough to recommend low dose or high dose regimen for routine induction of labour. Thus, further research is required to be carried out for the betterment of maternal and neonatal outcomes along with successful induction rates. ${ }^{9}$ Hence, this study is an attempt to evaluate effectiveness of low dose versus high dose regimen for induction of labour.

\section{METHODS}

A total of 100 antenatal patients who were admitted for induction of labour were enrolled in the study. All patients were randomised by block randomisation into two groups i.e. Group I and Group II, each consisting of 50 patients.

\section{Inclusion criteria}

Term nulliparous women with single live fetus in cephalic presentation.

\section{Exclusion criteria}

Uterine scar or any previous uterine surgery, weight of fetus more than $4 \mathrm{~kg}$, fetal malformations, medical conditions i.e. severe heart disease and severe anemia and any contraindication to vaginal delivery.

Primary outcome was estimation of Induction delivery interval. Secondary outcomes were rates of caesarean section, tachysystole with or without fetal distress, failed induction, maternal outcomes like incidence of instrumental vaginal delivery, PPH, chorioamnionitis, neonatal outcomes like admission to NICU, apgar score at 1 minutes and 5 minutes, umbilical cord $\mathrm{pH}$ and perinatal morbidity and mortality.

A detailed history, thorough clinical examination and relevant investigations were done for all the women. Vital signs of patient were obtained. Per vaginal examination was done to know the cervical status and the bishop score.

If bishop score was less than 6, pre-induction cervical ripening was done using dinoprostone gel $(0.5 \mathrm{mg})$ up to a maximum of 2 doses. If bishop was more than 6 , they were induced with Oxytocin according to the regimen assigned to her after block randomization.

Group I women received high-dose oxytocin regimen starting with $4 \mathrm{mu} / \mathrm{min}$ with increment of $4 \mathrm{mu} / \mathrm{min}$ every 30 min until adequate contractions (3-4 in $10 \mathrm{~min}$ ) were established or up to a maximum of $32 \mathrm{mu} / \mathrm{min}$.

Group II women received oxytocin at $2 \mathrm{mu} / \mathrm{min}$ with increment of $2 \mathrm{mu} / \mathrm{min}$ every $30 \mathrm{~min}$ until adequate contractions were established or up to a maximum of $32 \mathrm{mu} / \mathrm{min}$.

Uterine contractions and fetal heart rate were monitored by palpation and auscultation, respectively, with intermittent cardiotocographic (CTG) monitoring to identify fetal distress. If vaginal delivery was not achieved within 24 hours of oxytocin administration, induction was considered as 'failed' and further management was decided depending upon indication of induction.

In case of tachysystole ( $>5$ contractions per 10 minute period averaged over 30 minutes) with non-reassuring FHR pattern, oxytocin was discontinued, left lateral positioning was advised, IV bolus of $250-300 \mathrm{ml}$ ringer lactate and oxygen by mask at 8 -10liters/min was given.

If tachysystole occurred with reassuring fetal heart rate, then oxytocin was reduced to previous dose. If uterine activity did not return to normal, then oxytocin was stopped. If oxytocin had been stopped for 20min, FHR was reassuring and no tachysystole was present, then oxytocin was started at half the previous rate at which the tachysystole occurred and was thereafter increased every 
30 minutes until adequate uterine contractions were achieved or up to the maximum rate. All the events of induction of labour were recorded in excel sheet. Neonates were further followed for the adverse outcomes.

\section{Statistical analysis}

Categorical variables were presented in number and percentage $(\%)$ and continuous variables were presented as mean \pm SD and median. Normality of data was tested by Kolmogorov-Smirnov test. If the normality was rejected then non parametric test was used.

Statistical tests were applied as follows-

Quantitative variables were compared using Independent $\mathrm{T}$ test/Mann-Whitney Test (when the data sets were not normally distributed) between the two groups.

Qualitative variables were compared using Chi-Square test/Fisher's Exact test.

A $p$ value of $<0.05$ was considered statistically significant. The data was entered in MS EXCEL spreadsheet and analysis was done using Statistical Package for Social Sciences (SPSS) version 21.0.

\section{RESULTS}

\section{Demographic data and bishop's score}

Participant's basic characteristics such as mean age, parity, gestational age, indications for IOL, bishop's score, cervical dilatation were similar between the two groups as shown in Table 1 below.

All women were nulliparous. The most common indication for IOL in both groups was IHCP. Other indications are listed in Table 2.

\section{Primary outcome}

\section{Induction to delivery interval}

Women induced with high dose oxytocin regimen had shorter induction delivery interval as compared to low dose oxytocin interval by 2 hours 9 minutes. The outcome was found to be statistically significant ( $\mathrm{p}$ value 0.034) as shown in Table 3.

However, there was no difference in the duration of second stage of labour (group-1: $34.13 \pm 23.53$ minutes and group: $31.18 \pm 19.65$ minutes, p-value 0.546) among the two regimens.

Table 1: Comparison of demographic data and bishop's score in high dose and low dose oxytocin regimen.

\begin{tabular}{|llll|}
\hline Demographic data & $\begin{array}{l}\text { Group-I: 4mu/min } \\
(\mathbf{n = 5 0})\end{array}$ & Group-II:2/mu/min (n=50) & P value \\
\hline Age (years) & $27.86 \pm 3.84$ & $26.64 \pm 3.46$ & 0.098 \\
\hline Gestational age (weeks) & $38.44 \pm 0.86$ & $38.47 \pm 1.13$ & 0.876 \\
\hline Pre-induction agent (required) & $26(52 \%)$ & $25(50 \%)$ & 0.841 \\
\hline Post-induction bishop's score & $6.62 \pm 0.75$ & $6.8 \pm 0.81$ & 0.241 \\
\hline Cervical dilatation(cm) & $2.84 \pm 0.65$ & $2.68 \pm 0.59$ & 0.224 \\
\hline
\end{tabular}

Table 2: Comparison of indication of IOL between high dose and low dose oxytocin regimen.

\begin{tabular}{|c|c|c|c|c|c|}
\hline $\begin{array}{l}\text { Indication of } \\
\text { IOL }\end{array}$ & $\begin{array}{l}\text { High dose oxytocin } \\
\text { regimen }(n=50)\end{array}$ & $\begin{array}{l}\text { Low dose oxytocin } \\
\text { regimen }(n=50)\end{array}$ & Total & $\begin{array}{l}P \\
\text { value }\end{array}$ & $\begin{array}{l}\text { Test } \\
\text { performed }\end{array}$ \\
\hline FGR & $9(18 \%)$ & $8(16 \%)$ & $17(17 \%)$ & 0.992 & Fisher Exact tes \\
\hline $\begin{array}{l}\text { Gestational } \\
\text { diabetes mellitus }\end{array}$ & $5(10 \%)$ & $6(12 \%)$ & $11(11 \%)$ & & \\
\hline Gestational hypertension & $5(10 \%)$ & $4(8 \%)$ & $9(9 \%)$ & & \\
\hline IHCP & $18(36 \%)$ & $17(34 \%)$ & $35(35 \%)$ & & \\
\hline Postdated pregnancy & $7(14 \%)$ & $7(14 \%)$ & $14(14 \%)$ & & \\
\hline Preeclampsia & $2(4 \%)$ & $4(8 \%)$ & $6(6 \%)$ & & \\
\hline PROM & $4(8 \%)$ & $4(8 \%)$ & $8(8 \%)$ & & \\
\hline Total & $50(100 \%)$ & $50(100 \%)$ & $100(100 \%)$ & & \\
\hline
\end{tabular}

\section{Secondary outcomes}

The incidence of various maternal outcomes in the high dose and low dose oxytocin regimen were similar (Table 4).
The most common indications for LSCS in the two groups were fetal distress and failed induction. A special consideration is required for the incidence of tachysystole, which was more in high dose regimen as compared to low dose oxytocin regimen (table 4) but the 
difference was not statistically significant with a $\mathrm{p}$ value of 0.204 .

Neonatal outcomes were also not statistically different among the two regimens. The most common neonatal morbidity was neonatal jaundice (i.e. $\mathrm{n}=4(8 \%)$ in high dose and $n=6(12 \%)$ in low dose regimen which required admission to neonatal care unit. Umbilical cord $\mathrm{pH}$ was normal in all the patients. There was no maternal or perinatal mortality.

Table 3: Comparison of induction delivery interval (in hours) between high dose and low dose oxytocin regimen.

\begin{tabular}{|c|c|c|c|c|c|}
\hline $\begin{array}{l}\text { Induction } \\
\text { delivery interval } \\
\text { (in hours) }\end{array}$ & $\begin{array}{l}\text { High dose oxytocin } \\
\text { regimen }(n=39)\end{array}$ & $\begin{array}{l}\text { Low dose oxytocin } \\
\text { regimen }(n=40)\end{array}$ & Total & $\begin{array}{l}P \\
\text { value }\end{array}$ & $\begin{array}{l}\text { Test } \\
\text { performed }\end{array}$ \\
\hline Mean \pm Std. dev & $6.96 \pm 3.77$ & $9.05 \pm 4.65$ & $8.01 \pm 4.34$ & \multirow{3}{*}{0.034} & \multirow{3}{*}{$\begin{array}{l}\text { Mann Whitney } \\
\text { test; } \\
564.5\end{array}$} \\
\hline Median (IQR) & $5.8(3.825-8.808)$ & $7.54(6.333-11.417)$ & $7.08(4.708-10.5)$ & & \\
\hline Range & $2.35-15.75$ & $3.5-23.5$ & $2.35-23.5$ & & \\
\hline
\end{tabular}

Table 4: Comparison of secondary outcomes in high dose and low dose oxytocin regimen.

\begin{tabular}{|llll|}
\hline Outcomes & $\begin{array}{l}\text { Group-I: 4mu/min } \\
(\mathbf{n}=\mathbf{5 0})\end{array}$ & $\begin{array}{l}\text { Group-II:2mu/min } \\
(\mathbf{n}=\mathbf{5 0})\end{array}$ & P value \\
\hline Maternal outcomes & $11(22 \%)$ & $10(20 \%)$ & 0.806 \\
\hline Need for LSCS & $1(2 \%)$ & $2(4 \%)$ & 1 \\
\hline Instrumental vaginal delivery & $5(10 \%)$ & $5(10 \%)$ & 0.204 \\
\hline Failed induction & $5(10 \%)$ & $1(2 \%)$ & 0.749 \\
\hline Tachysystole & $6(12 \%)$ & $5(10 \%)$ & 1 \\
\hline Fetal distress & $3(6 \%)$ & $3(6 \%)$ & 1 \\
\hline PPH & $1(2 \%)$ & $0(0 \%)$ & 0.7411 \\
\hline Chorioamnionitis & & & 0.741 \\
\hline Neonatal outcomes (APGAR score) & $7.76 \pm 0.66$ & $7.7 \pm 0.54$ & $8.74 \pm 0.49$ \\
\hline At 1 min & $8.74 \pm 0.49$ & $6(12 \%)$ & \\
\hline At 5 min & $4(8 \%)$ & &
\end{tabular}

\section{DISCUSSION}

Active management of labour is a very delicate process in obstetrics. It requires utmost attention in order to reduce maternal and neonatal morbidity and mortality along with high success rates. In the present era, there exists considerable controversy and lack of evidence about oxytocin administration and dosage.

This randomized comparative study is an attempt to bring forth some of the important aspects of oxytocin regimen and its effect on various outcomes.

The primary outcome of the study, induction to delivery interval, was found to be statistically shorter in high dose oxytocin regimen as compared to low dose oxytocin regimen by 2 hours 9 minutes ( $p$ value 0.034 ). In a systemic review (2010) Wei SQ et al, decrease in labour duration (mean difference 1.54 hours, $95 \% \mathrm{CI},-2.44$ to 0.64 ) along with a small increase in spontaneous vaginal delivery (RR, 1.07; 95\% CI, 1.02-1.12) was observed with high dose oxytocin regimen as compared to low dose oxytocin regimen. ${ }^{7}$
Similarly, studies by Rintaro Mori et al in 2011 and A. Ghidini et al in 2012 reported significant reduction in length of labour duration in high dose oxytocin regimen when compared with that of low dose oxytocin regimen. 13,14

Cochrane systemic reviews and metaanalysis (2016) showed that removal of high bias studies revealed a significant detailed reduction of induction to delivery interval (MD -1.94 hours, 95\% CI -0.99 to -2.89 hours, 489 women). ${ }^{9}$

In a recent randomised controlled trial by L. Selin et al (2018), duration of labour was found to be 23 minutes shorter with high-dose regimen of oxytocin (mean difference $23.4 \mathrm{~min}, 95 \% \mathrm{CI} 45.1$ to 1.5 , p value 0.021 ) when compared with that of low dose regimen. ${ }^{8}$

Similarly, in a multicentre comparative study conducted by Tesemma MG et al in 2020, the mean "Induction to delivery time" was $5.9 \mathrm{hr}$ and $6.3 \mathrm{hr}$ for participants who received high dose Oxytocin and low dose Oxytocin respectively showing mothers receiving high dose 
oxytocin regimen had slightly shorter duration of labour. $^{10}$

In the present study, high dose oxytocin regimen had increased incidence of uterine tachysystole, but the difference was not statistically significant. In a Cochrane review by A.Budden et al significant increase in hyperstimulation was reported without specifying fetal heart rate changes in the high-dose group. ${ }^{9}$ Also, B. G. Manjula et al (2014) reported an increased rate of tachysystole in patients induced with high dose oxytocin regimen ( $\mathrm{p}$ value 0.0040$).{ }^{15}$

The proportion of women experiencing adverse events did not differ significantly between the two regimens. Hereby, taking into account all the above outcomes and interpretations, we concluded that high dose oxytocin regimen can be considered for induction of labour as it has same effects as that of low dose regimen with lesser induction to delivery interval.

The limitation of the present study was small sample size. Hence, the results of the study cannot be extrapolated to the general population. The effects of some of the outcomes like uterine tachysystole could have been significant had the sample size been more.

Also, the study included only nulliparous women. The effect of both the regimens was not studied on multiparous women or women with previous ceasarean section.

\section{CONCLUSION}

On the basis of present study, high dose oxytocin regimen can be considered for induction of labour as it has same effects as that of low dose regimen with lesser induction to delivery interval.

\section{Funding: No funding sources}

Conflict of interest: None declared

Ethical approval: The study was approved by the Institutional Ethics Committee

\section{REFERENCES}

1. Goel K, Gedam JK, Rajput DA, Bhalerao M V. Induction of Labor: A Review. Indian J Clin Pract. 2014;24(11):105-64.

2. WHO recommendation for induction of labour. Geneva: World Health Oraganisation 2011. Available at http://whqlibdoc.who.int/hq/2011/WHO_RHR_11.10 _eng.pdf.

3. WHO Global Survey on Maternal and Perinatal Health. Induction of labour data. Geneva: World health Organization 2010. Available at http://www .who.int/reproductivehealth/topics

/best_practices/global_survey.

4. Maul H, MacKay L, Garfield RE. Cervical ripening: Biochemical, molecular, and clinical considerations. Clin Obstet Gynecol. 2006;49(3):551-63.

5. Royal College of Obstetricians and Gynaecologists (RCOG). Induction of labour, Evidence-based Clinical Guideline Number 9. RCOG Clinical Effectiveness Support Unit, London: RCOG Press;2001.

6. The American Congress of Obstetrician and Gynecologists (ACOG). Optimizing Protocols in Obstetrics: Oxytocin for induction. 2011;10-3. Available from http://mail.ny.acog.org/website/OxytocinForInductio n.pdf.

7. Wei SQ, Luo ZC, Qi HP, Xu H, Fraser WD. Highdose vs low-dose oxytocin for labor augmentation: A systematic review. Am J Obstet Gynecol. 2010;203(4):296-304.

8. Selin L, Wennerholm UB, Jonsson M, Dencker A, Wallin G, Wiberg-Itzel E, et al. High-dose versus low-dose of oxytocin for labour augmentation: a randomised controlled trial. Women and Birth. 2019;32(4):356-63.

9. Budden A, Chen LJY, Henry A. High-dose versus low-dose oxytocin infusion regimens for induction of labour at term. 2014;10:CD009701.

10. Tesemma MG, Sori DA, Gemeda DH. High dose and low dose oxytocin regimens as determinants of successful labor induction: a multicenter comparative study. BMC Pregnancy Childbirth. 2020;20(1):4-11.

11. Prichard N, Lindquist A, Hiscock R, Ruff S, Tong S, Brownfoot FC. High-dose compared with low-dose oxytocin for induction of labour of nulliparous women at term. J Matern Neonatal Med. 2019;32(3):362-8.

12. Hourvitz A, Alcalay M, Korach J, Lusky A, Barkai G, Seidman DS. A prospective study of high- versus low-dose oxytocin for induction of labor. Acta Obstet Gynecol Scand. 1996;75(7):636-bv ccv41.

13. Mori R, Tokumasu H, Pledge D, Kenyon S. High dose versus low dose oxytocin for augmentation of delayed labour. 2011;10:CD007201.

14. Ghidini A, Wohlleb D, Korker V, C. Pezzullo J, H. Poggi S. Effects of two different protocols of oxytocin infusion for labor induction on obstetric outcomes: A cohort study. Open J Obstet Gynecol. 2012;02(02):106-11.

15. Manjula BG, Bagga R, Kalra J, Dutta S. Labour induction with an intermediate-dose oxytocin regimen has advantages over a high-dose regimen. $\mathrm{J}$ Obstet Gynaecol. 2014;35(4):362-7.

Cite this article as: Gupta P, Chawala I, Gupta S. Effectiveness of low dose versus high dose oxytocin regimen for induction of labour. Int $\mathbf{J}$ Reprod Contracept Obstet Gynecol 2021;10:1948-52. 